Research Paper

\title{
Geraniin attenuates LPS-induced acute lung injury via inhibiting NF-KB and activating Nrf2 signaling pathways
}

\author{
Guangfa Zhu ${ }^{1,2}$, Xi Xin ${ }^{1}$, Yan Liu ${ }^{2}$, Yan Huang ${ }^{1}, K_{\text {Keng }} \mathbf{L i}^{2}$, Chunting Wu${ }^{1}$ \\ ${ }^{1}$ Department of Pulmonary and Critical Care Medicine, Beijing Anzhen Hospital, Capital Medical University, Beijing Institute \\ of Heart, Lung and Blood Vessel Diseases, Beijing 100029, P.R. China \\ ${ }^{2}$ Department of Infectious Diseases, Beijing Anzhen Hospital, Capital Medical University, Beijing Institute of Heart, Lung and \\ Blood Vessel Diseases, Beijing 100029, P.R. China
}

Correspondence to: Guangfa Zhu, email: guangfa_zhu@yahoo.com

Keywords: geraniin, LPS, Nrf2, lung injury

Received: November 16, $2016 \quad$ Accepted: January 13, 2017

Published: February 09, 2017

\section{ABSTRACT}

Geraniin, a typical ellagitannin isolated from Phyllanthusurinaria Linn, has been reported to have anti-inflammatory effect. The aim of the study is to investigate the therapeutic effects of geraniin on LPS-induced acute lung injury (ALI) in mice. The mice were intranasal adminisration of LPS for $12 \mathrm{~h}$. Geraniin was intra-peritoneal injection $1 \mathrm{~h}$ after LPS treatment. The results showed that geraniin significantly attenuated LPS-induced pathological changes in the lung. Geraniin also inhibited LPS-induced macrophages and neutrophils infiltration in the lung. Geraniin significantly attenuated LPS-induced elevation of MPO level. LPS-induced TNF- $a$, IL-6 and IL-1 $\beta$ production were markedly suppressed by treatment of geraniin. Furthermore, geraniin inhibited NF-KB activation in LPS-induced ALI. In addition, geraniin was found to up-regulate the expression of Nrf2 and HO-1. In conclusion, these data suggested that geraniin had therapeutic effects in LPS-induced ALI by inhibiting NF-KB and activating Nrf2 signaling pathways.

\section{INTRODUCTION}

Acute lung injury (ALI) is a critical pulmonary inflammatory disease that characterized by progressive hypoxemia, edema, and neutrophil accumulation in the lung [1]. Previous studies have suggested that Lipopolysaccharide (LPS) was the major stimulus of ALI and inflammation played a critical role in the pathogenesis of ALI [2]. LPS could induce the production of inflammatory mediators via NF- $\mathrm{KB}$ signaling pathway [3]. These inflammatory mediators amply the inflammatory response and lead to lung injury [4]. ALI is often associated with high morbidity and mortality in ill patients [5, 6]. Despite recent advances in intense care research of acute lung injury, its incidence remains high $[7,8]$. Therefore, an effective therapeutic option against ALI drug is urgently required. Nrf2, an important transcription factor, can be activated by redox-dependent stimuli. Previous studies showed that activating Nrf2 could regulate inflammatory and oxidative stress [9]. Furthermore, activating Nrf2 could inhibit lung injury [10]. Therefore, Nrf2 may used as a target in the treatment of lung injury.

Geraniin, a typical ellagitannin extracted from Phyllanthusurinaria Linn, has been reported to have anti-oxidant and anti-inflammatory activities [11]. Geraniin was found to inhibit LPS-induced inflammation in RAW264.7 cells [12]. Also, geraniin was found to inhibit LPS-induced THP-1 macrophages switching to M1 phenotype [13]. Furthermore, it has been reported that geraniin protected cells from $\mathrm{H}_{2} \mathrm{O}_{2}$-induced oxidative cell death [14]. In addition, studies showed that geraniin protected liver cells against ethanol induced cytotoxicity [15]. However, whether geraniin could protect against LPS-induced acute lung injury was uncertain. Therefore, we investigated the protective effects of geraniin on LPS-induced ALI in mice.

\section{RESULTS}

Geraniin reduces inflammatory cells infiltration in LPS-induced lung injury

The effects of geraniin on inflammatory cells infiltration were measured in this study. As shown in Figure 1, compared with the control group, LPS significantly increased the numbers of total cells, neutrophils and macrophages. However, this increases induced by LPS was reduced with the administration of geraniin in a dose dependent manner. 


\section{Effects of Geraniin on LPS-induced lung histopathological changes}

In this study, we detected the effects of geraniin on LPS-induced lung histopathological changes (Figure 2A). In the LPS group without treatment of geraniin, lung tissues showed evident histopathological abnormalities, evidenced by the presence of alveolar wall thickness, airalveoli, emphysematous and pulmonary congestion (Figure 2B). However, compared with LPS group, the histopathological changes of lung tissues were improved by geraniin administration (Figure 2C-2E).

\section{Effects of geraniin on MOP activity and lung W/D ratio}

MPO activity, a biomarker of neutrophils, was detected in this study. As shown in Figure 3, compared with the control group, LPS significantly increased MPO activity in lung tissues. However, this increase induced by LPS was reduced with the administration of geraniin in a dose dependent manner. The effects of geraniin on LPSinduced lung W/D ratio were also measured. The results showed that LPS significantly increased lung W/D ratio. However, geraniin significantly inhibited LPS-induced lung W/D ratio (Figure 3).

\section{Effects of geraniin on cytokine production in BALF}

BALF was collected to determine the effects of geraniin on LPS-induced inflammatory cytokines production. Compared with the control group, the results showed that LPS significantly increased the levels of TNF- $\alpha$, IL- $1 \beta$, and IL- 6 in BALF. However, treatment of geraniin dose-dependently reduced TNF- $\alpha$, IL- $1 \beta$, and IL-6 production compared with LPS group (Figure 4).

\section{Effects of geraniin on LPS-induced NF-кB activation}

Western blot were performed to determine the

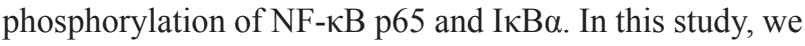

found that LPS increased the phosphorylation of NF- $\mathrm{BB}$ $\mathrm{p} 65$ and I $\kappa \mathrm{B} \alpha$. However, treatment with geraniin decreased

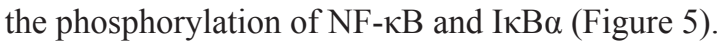

\section{Effects of geraniin on HO-1 and Nrf2 expression}

To investigate the anti-inflammatory mechanism of geraniin, the effects of geraniin on Nrf2 signaling pathway were detected. Compared with the control group, increased the expression of Nrf2 and HO-1. However, treatment of geraniin dose-dependently up-regulated the expression of Nrf2 and HO-1 (Figure 6).

\section{DISCUSSION}

In this study, we report for the first time that geraniinhas therapeutic effect against LPS-induced ALI. Geraniin attenuates LPS-induced ALI by inhibiting inflammatory mediators production. The pharmacological actions of geraniin were associated with the activation of Nrf2 and inhibition of NF- $\kappa$ B signaling pathways.

In LPS-induced ALI, exposure of lungs to LPS leads to the release of inflammatory cytokines, such as TNF- $\alpha$, IL-1 $\beta$, IL-6 via NF- $\kappa B$ signaling pathway [16]. These inflammatory cytokines amply the inflammatory response and lead to the pathogenesis of ALI [17]. Furthermore, these inflammatory cytokines could induce the infiltration of neutrophilsand damage alveolar epithelial permeability and lead to lung edema $[18,19]$. Previous studies showed that inhibition of these inflammatory cytokines could attenuate the pathogenesis of ALI [20]. In this study, we found that geraniin significantly inhibited LPSinduced inflammatory cytokines production. In addition, the infiltration of neutrophils and lung edema were also suppressed by treatment of geraniin. These results indicated that geraniin protected against LPS-induced ALI by inhibiting inflammatory cytokines production.

A growing body of studies showed that NF$\kappa \mathrm{B}$ signaling pathway played an important role in the pathophysiology of ALI [21]. In our previous study, we found that inhibition of NF- $\mathrm{KB}$ could protect sepsisinduced ALI in mice [22]. Normally, NF-KB is located in the cytoplasm with inhibitory protein IKB. LPS could
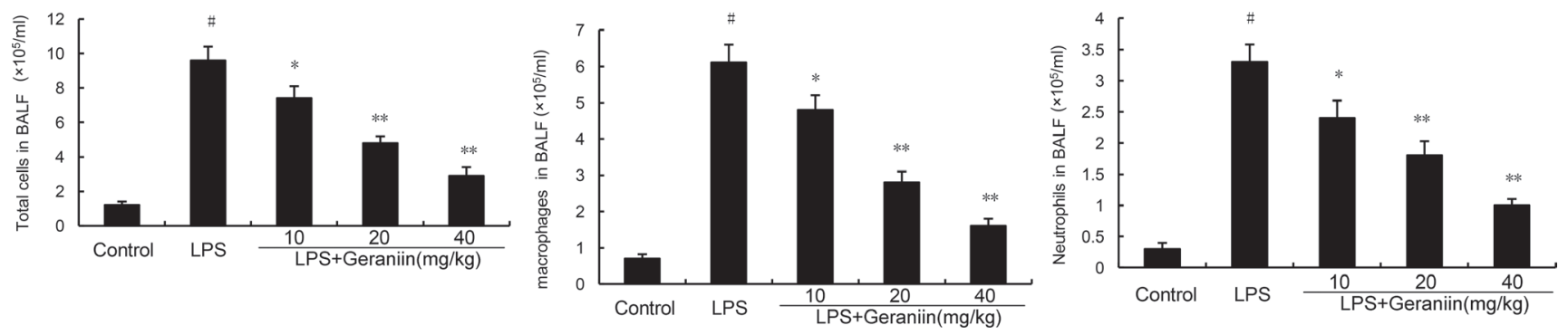

Figure 1: Effects of geraniin on inflammatory inflammatory cells infiltration in the BALF. $12 \mathrm{~h}$ after LPS treatment, the BALF were collected and the numbers of inflammatory cells were detected. The values presented are the mean $\pm \mathrm{SEM}$ of three independent experiments. ${ }^{*} p<0.01$ vs. control group, ${ }^{*} p<0.05,{ }^{* *} p<0.01$ vs. LPS group. 


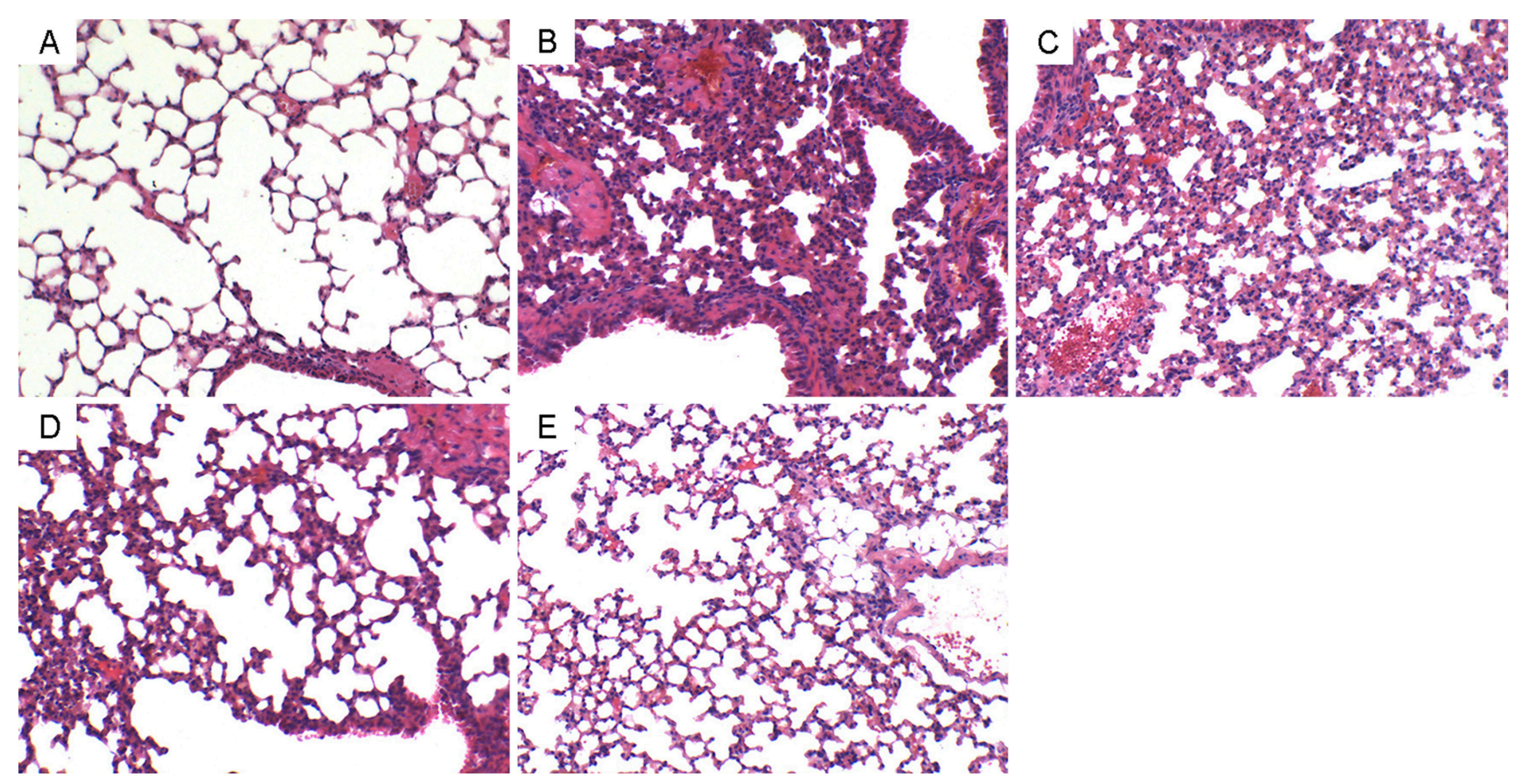

Figure 2: Effects of geraniinon histopathological changes in lung tissues in LPS-induced ALI mice. Representative histological changes of lung obtained from mice of different groups. (A) Control group, (B) LPS group, (C) LPS + geraniin (10 mg/kg) group, (D) LPS + geraniin $(20 \mathrm{mg} / \mathrm{kg}$ ) group (E) LPS + geraniin $(40 \mathrm{mg} / \mathrm{kg})$ group (Hematoxylin and eosin staining, magnification $200 \times)$.
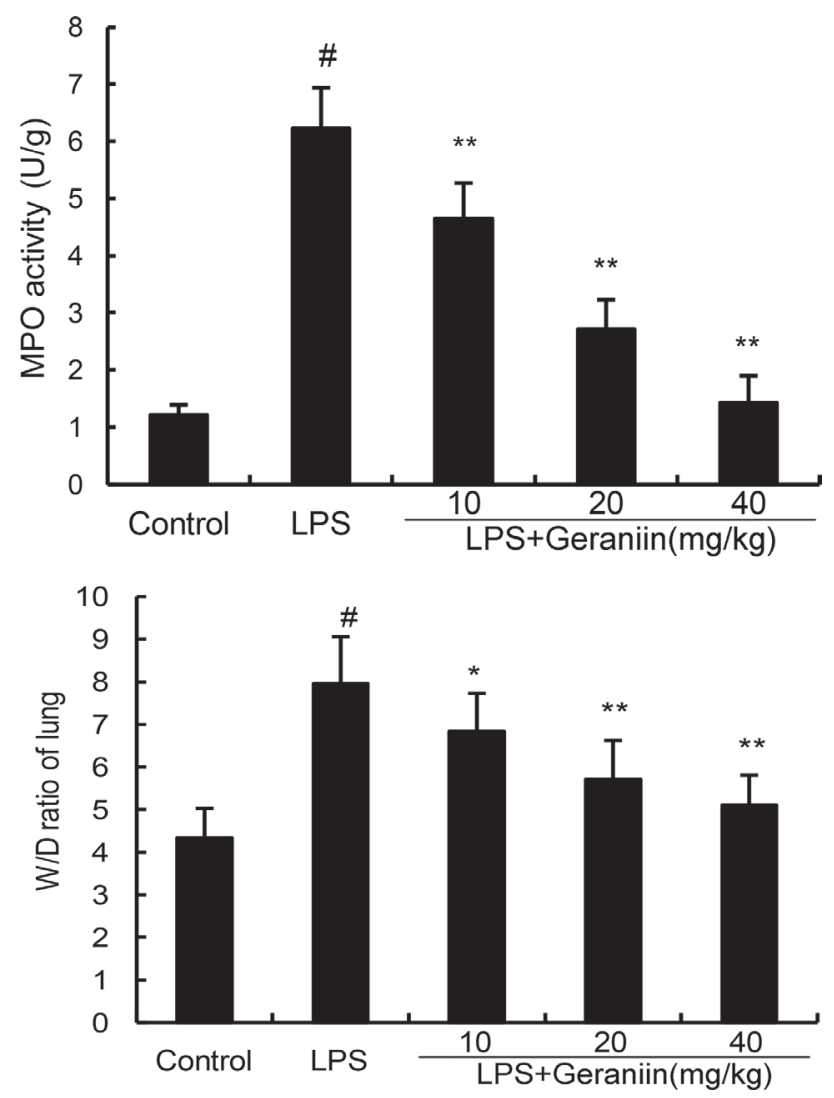

Figure 3: Effects of geraniin on MPO activity and lung W/D ratioof LPS-induced ALI. $12 \mathrm{~h}$ after LPS treatment, the lung tissues were collected and MPO activity was detected. The values presented are the mean \pm SEMof three independent experiments. ${ }^{\#} p<0.01$ vs. control group, ${ }^{*} p<0.05,{ }^{* *} p<0.01$ vs. LPS group. 

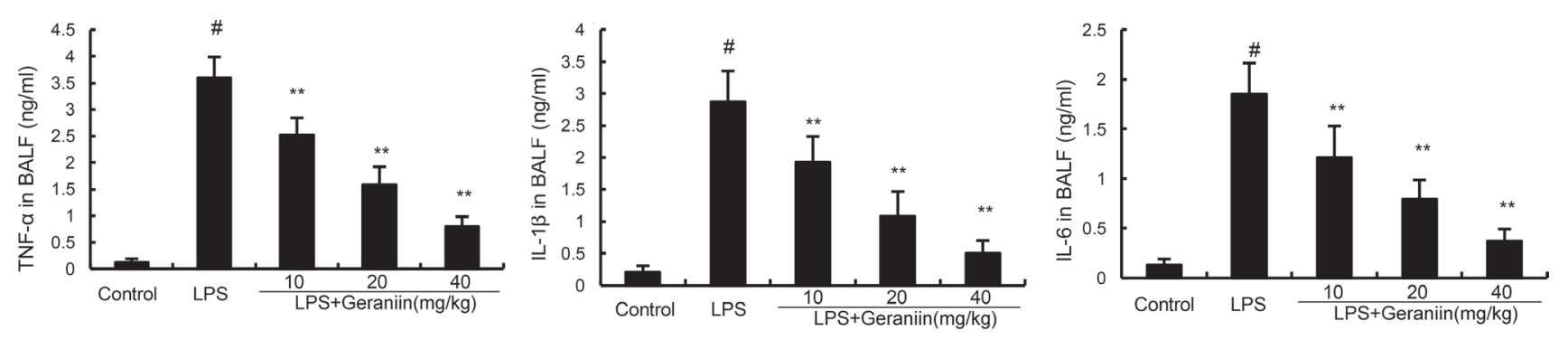

Figure 4: Effects of geraniin on TNF- $\alpha$, IL-1ß, and IL-6 production in the BALF of LPS-induced ALI mice. $12 \mathrm{~h}$ after LPS treatment, the BALF were collected and the levels of TNF- $\alpha$, IL-1ß, and IL- 6 were detected. The values presented are mean \pm SEM of three independent experiments. ${ }^{\#} p<0.01$ vs. control group, ${ }^{*} p<0.05,{ }^{* *} p<0.01$ vs. LPS group.

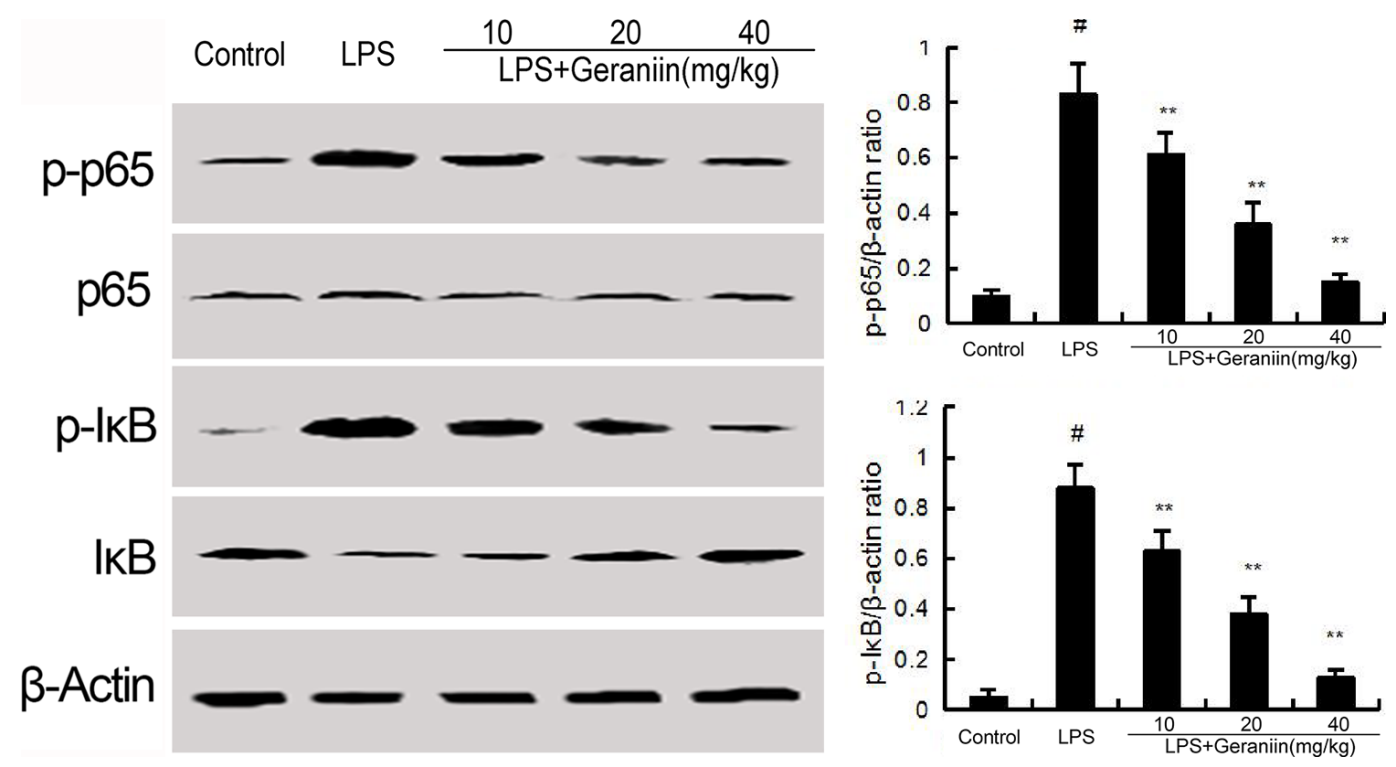

Figure 5: Geraniin inhibits LPS-induced NF-кB activation. The values presented are the means \pm SEM of three independent experiments. ${ }^{\#} p<0.01$ vs. control group, ${ }^{*} p<0.05,{ }^{* *} p<0.01$ vs. LPS group.

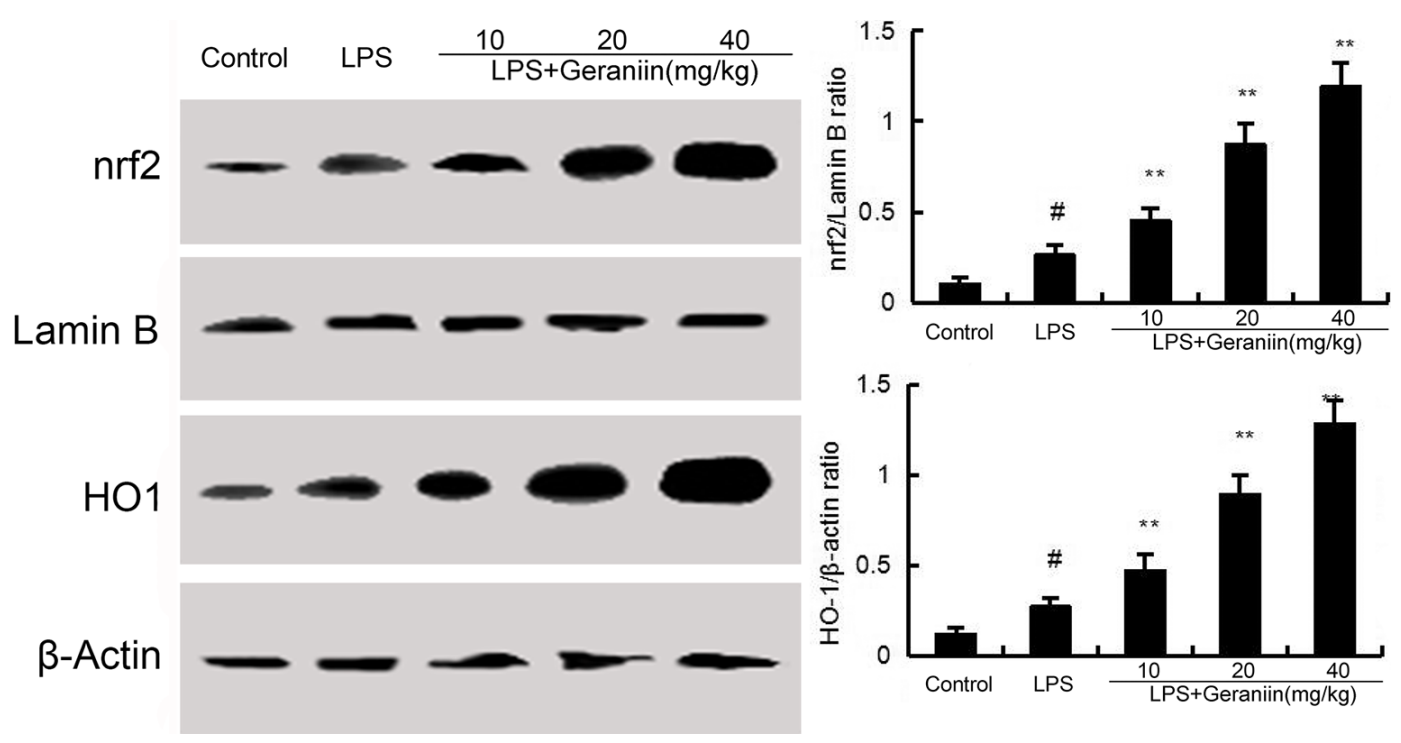

Figure 6: Effects of geraniin on Nrf2 signaling pathway. The values presented are the means \pm SEM of three independent experiments. ${ }^{\sharp} p<0.01$ vs. control group, ${ }^{*} p<0.05,{ }^{* *} p<0.01$ vs. LPS group. 


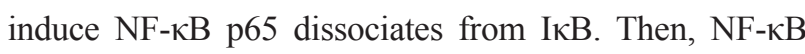
p65 translocates into the nucleus to induce the expression of inflammatory cytokines $[23,24]$. Inhibiting of NF- $\kappa \mathrm{B}$ signaling pathway could attenuate LPS-induced ALI by inhibiting inflammatory cytokines production $[25,26]$. To clarify the anti-inflammatory mechanism of geraniin, the effects of geraniinon $\mathrm{NF}-\kappa \mathrm{B}$ activation were measured. The results suggested that geraniin significantly inhibited LPS-induced NF- $\kappa \mathrm{B}$ activation. The transcription factor Nrf2 regulates the expression of antioxidant genes [27] and previous studies suggested that Nrf2 affected the severity of acute lung injury [28]. Studies showed that deletion of Nrf2 in airway epithelium exacerbated acute lung injury and attenuated the inflammatory response [29]. In addition, it has been reported that activation of Nrf2 could attenuate LPS-induced lung injury [30]. In previous study, our results showed that eriodictyol protected LPS-induced ALI by activating Nrf2 [31]. These results suggested that Nrf2 had protective effects against acute lung injury. In this study, our results showed that geraniin up-regulated the expression of Nrf2 and HO-1 in a dose dependent manner. These results suggested that geraniin protected against LPS-induced lung injury by activating Nrf2 signaling pathway.

In conclusion, our results showed that geraniin had therapeutic effects against LPS-induced ALI. The beneficial effects of geraniin are due to its anti-inflammatory effects. Geraniin exhibited anti-inflammatory effects by inhibiting $\mathrm{NF}-\kappa \mathrm{B}$ and activating Nrf2 signaling pathways. Geraniin may serve as a novel agent for the treatment of ALI.

\section{MATERIALS AND METHODS}

\section{Reagents}

Geraniin (purity > 98\%) was purchased from the Chinese Institute for Drug and Biological Product Control (Beijing, China).LPS was purchased from Sigma Chemical Co. (St. Louis, MO, USA). Mouse TNF- $\alpha, I L-6$ and IL-1 $\beta E L I S A$ kits were obtained from BioLegend (CA, USA).Antibodies for Nrf2, HO-1, NF- $\kappa \mathrm{B}$ p65, I $\kappa \mathrm{B} \alpha$, and $\beta$-actin were purchased from CST (Danvers, MA, USA).

\section{Animals}

BALB/c mice (6-8 weeks) were purchased from the Center of Experimental Animals of Capital Medical University (Beijing, China). The mice were received a standard diet and housed in a room with controlled temperature. The mice were adapted the environment for 7 days. All animal experimental procedures were approved by the Committee of Animal Experimentation of the Capital Medical University.

\section{Experimental design}

Sixty mice were randomly divided into five groups and each group contains 12 mice. Group A,the control group; group B, LPS group; group $\mathrm{C}$ to $\mathrm{E}, \mathrm{LPS}+$ geraniin $(10,20$ and $40 \mathrm{mg} / \mathrm{kg})$ groups. The mice of Group B were received with $50 \mu \mathrm{L}$ LPS given byintranasally (i.n.). The mice of $\mathrm{C}$ to $\mathrm{E}$ groups were received with $50 \mu \mathrm{L}$ LPS given byintranasally (i.n.). $1 \mathrm{~h}$ later, geraniin $(10,20$ and $40 \mathrm{mg} / \mathrm{kg}$ ) was given to mice. The doses of geraniin were based on previous study [32]. The mice of Group A were given equal amount of PBS. $12 \mathrm{~h}$ after LPS treatment, the mice were killed and the BALF were collected. We chose $12 \mathrm{~h}$ after LPS treatment was based on previous studies [33].

\section{Histopathologic evaluation of lung tissues}

Lung tissue was fixed with $10 \%$ buffered formalin for $12 \mathrm{~h}$, paraffin embedded and cut into 5 - $\mu \mathrm{m}$ sections. After the section were stained with hematoxylin and eosin (H\&E), the sections were observed with a microscope (Olympus, Tokyo, Japan), as described previously.

\section{BALF and cell count}

$12 \mathrm{~h}$ after LPS treatment, the mice were killed and the BALF were collected. The number of total cells was counted using a hemocytometer. The numbers of neutrophils and macrophages in BALF were stained with the Kwik-Diff staining set (Thermo, USA).

\section{MPO assay}

MPO activity was measured to demonstrate the neutrophil infiltration using the myeloperoxidase fluorometric activity assay kit (Sigma). $12 \mathrm{~h}$ after LPS challenge, the mice were killed and the lung tissues were collected and homogenized in cool normal saline. Then the MPO activity was measured using test kits purchased from multi-mode microplate reader (BioTek, SynergyHT, Bedfordshire, United Kingdom).

\section{Inflammatory cytokines assay}

Specific ELISA kits (BioLegend, CA, USA) were used to quantify TNF- $\alpha$, IL- $1 \beta$, and IL- 6 in the BALF. The standard curve was established according to the standards provided by the kits.

\section{Lung W/D ratio}

The inferior lobe of the right lung was collected to obtain the 'wet' weight. Then, the lung was dried at $80^{\circ} \mathrm{C}$ for $48 \mathrm{~h}$ to obtain the 'dry' weight. The lung W/D ratio was calculated by dividing the lung wet weight by the lung dry weight.

\section{Western blot analysis}

Total proteins from lung microglia were extracted by M-PER Mammalian Protein Extraction reagent (Thermo, 
USA). Samples with equal amounts (40 $\mu \mathrm{g})$ of protein were fractionated on $10 \%$ SDS-polyacrylamide gel and transferred on nitrocellulose membranes. The membranes were blocked with $5 \%$ bovine serum albumin. Then, the membranes were probed with the primary antibodies and secondary antibodies at room temperature. The proteins were measured using the ECL detection reagents (BioLegend, CA, USA).

\section{Statistical analyses}

Data are expressed in terms of mean $\pm \mathrm{SD}$. Data were analyzed by using one-way analysis of variance followed by post-hoc Dunnett's test with a significancelevel of $p<0.05$. Statistical analyseswere performed using the SPSS software package.

\section{CONFLICTS OF INTEREST}

All authors declare that they have no conflicts of interest.

\section{GRANT SUPPORT}

This work was partly supported by a grant (SF-2016-2-1052) from the Capital health development research and special projects of Beijing (Risk factors and prediction score of acute respiratory distress syndrome after cardiac surgery).

\section{REFERENCES}

1. Geiser T, Atabai K, Jarreau PH, Ware LB, Pugin J, Matthay MA. Pulmonary edema fluid from patients with acute lung injury augments in vitro alveolar epithelial repair by an IL-1 beta-dependent mechanism. American journal of respiratory and critical care medicine. 2001; 163:1384-1388.

2. Zhang B, Liu ZY, Li YY, Luo Y, Liu ML, Dong HY, Wang YX, Liu Y, Zhao PT, Jin FG, Li ZC. Antiinflammatory effects of matrine in LPS-induced acute lung injury in mice. Eur J Pharm Sci. 2011; 44:573-579.

3. Ghosh S, Hayden MS. New regulators of NF-kappa B in inflammation. Nat Rev Immunol. 2008; 8:837-848.

4. Welbourn CR, Young Y. Endotoxin, septic shock and acute lung injury: neutrophils, macrophages and inflammatory mediators. The British journal of surgery. 1992; 79:998-1003.

5. Gajic O, Rana R, Winters JL, Yilmaz M, Mendez JL, Rickman OB, O’Byrne MM, Evenson LK, Malinchoc M, DeGoey SR, Afessa B, Hubmayr RD, Moore SB. Transfusionrelated acute lung injury in the critically ill: prospective nested case-control study. American journal of respiratory and critical care medicine. 2007; 176:886-891.

6. O’Brien JM, Phillips GS, Ali NA, Lucarelli M, Marsh CB, Lemeshow S. Body mass index is independently associated with hospital mortality in mechanically ventilated adults with acute lung injury. Critical care medicine. 2006; 34:738-744.

7. Johnson ER, Matthay MA. Acute Lung Injury: Epidemiology, Pathogenesis, and Treatment. J Aerosol Med Pulm D. 2010; 23:243-252.

8. Estenssoro E, Dubin A, Laffaire E, Canales C, Saenz G, Moseinco M, Pozo M, Gomez A, Baredes N, Jannello G, Osatnik J. Incidence, clinical course, and outcome in 217 patients with acute respiratory distress syndrome. Critical care medicine. 2002; 30:2450-2456.

9. Cho HY, Reddy SP, Yamamoto M, Kleeberger SR. The transcription factor NRF2 protects against pulmonary fibrosis. FASEB journal. 2004; 18:1258-1260.

10. Reddy NM, Kleeberger SR, Kensler TW, Yamamoto M, Hassoun PM, Reddy SP. Disruption of Nrf2 impairs the resolution of hyperoxia-induced acute lung injury and inflammation in mice. J Immunol. 2009; 182:7264-7271.

11. Boakye YD, Agyare C, Abotsi WK. Anti-inflammatory activity of geraniin and aqueous extract of Phyllanthus muellerianus (Kuntze) Exell. Planta Med. 2013; 79:1142-1142.

12. Wang P, Qiao Q, Li J, Wang W, Yao LP, Fu YJ. Inhibitory effects of geraniin on LPS-induced inflammation via regulating NF-kappa B, Nrf2 pathways in RAW 264.7 cells. Chem-Biol Interact. 2016; 253:134-142.

13. Liu XX, Li J, Peng XH, Lv B, Wang P, Zhao XM, Yu B. Geraniin Inhibits LPS-Induced THP-1 Macrophages Switching to M1 Phenotype via SOCS1/NF-kappa B Pathway. Inflammation. 2016; 39:1421-1433.

14. Wang P, Peng X, Wei ZF, Wei FY, Wang W, Ma WD, Yao LP, $\mathrm{Fu}$ YJ, Zu YG. Geraniin exerts cytoprotective effect against cellular oxidative stress by upregulation of Nrf2-mediated antioxidant enzyme expression via PI3K/AKT, ERK1/2 pathway. Bba-Gen Subjects. 2015; 1850:1751-1761.

15. Londhe JS, Devasagayam TPA, Foo LY, Shastry P, Ghaskadbi SS. Geraniin and amariin, ellagitannins from Phyllanthus amarus, protect liver cells against ethanol induced cytotoxicity. Fitoterapia. 2012; 83:1562-1568.

16. Chen XJ, Yang XF, Liu TJ, Guan MF, Feng XR, Dong W, Chu X, Liu J, Tian XL, Ci XX, Li HY, Wei JY, Deng YH, et al. Kaempferol regulates MAPKs and NF-kappa B signaling pathways to attenuate LPS-induced acute lung injury in mice. Int Immunopharmacol. 2012; 14:209-216.

17. Goodman RB, Pugin J, Lee JS, Matthay MA. Cytokinemediated inflammation in acute lung injury. Cytokine \& growth factor reviews. 2003; 14:523-535.

18. Ganter MT, Roux J, Miyazawa B, Howard M, Frank JA, Su G, Sheppard D, Violette SM, Weinreb PH, Horan GS, Matthay MA, Pittet JF. Interleukin-1 beta causes acute lung injury via alpha $\mathrm{v}$ beta 5 and alpha $\mathrm{v}$ beta 6 integrin-dependent mechanisms. Circ Res. 2008; 102:804-812.

19. Strieter RM, Kunkel SL. Acute lung injury: the role of cytokines in the elicitation of neutrophils. Journal of investigative medicine. 1994; 42:640-651.

20. Zhang B, Liu ZY, Li YY, Luo Y, Liu ML, Dong HY, Wang YX, Liu Y, Zhao PT, Jin FG, Li ZC. Antiinflammatory 
effects of matrine in LPS-induced acute lung injury in mice. Eur J Pharm Sci. 2011; 44:573-579.

21. Imai Y, Kuba K, Neely GG, Yaghubian-Malhami R, Perkmann T, van Loo G, Ermolaeva M, Veldhuizen R, Leung YHC, Wang HL, Liu HL, Sun Y, Pasparakis M, et al. Identification of oxidative stress and toll-like receptor 4 signaling as a key pathway of acute lung injury. Cell. 2008; 133:235-249.

22. Jin LY, Li CF, Zhu GF, Wu CT, Wang J, Yan SF. Effect of siRNA against NF-kappa B on sepsis-induced acute lung injury in a mouse model. Mol Med Rep. 2014; 10:631-637.

23. Silverman N, Maniatis T. NF-kappa B signaling pathways in mammalian and insect innate immunity. Gene Dev. 2001; 15:2321-2342.

24. Hoffmann A. The I kappa B-NF-kappa B signaling module: Temporal control and selective gene activation. Science. 2002; 298:1241-1245.

25. Shen WF, Gan JX, Xu SW, Jiang GY, Wu HH. Penehyclidine hydrochloride attenuates LPS-induced acute lung injury involvement of NF-kappa B pathway. Pharmacological research. 2009; 60:296-302.

26. Everhart MB, Wei H, Sherrill TP, Arutiunov M, Polosukhin VV, Burke JR, Sadikot RT, Christman JW, Yull FE, Blackwell TS. Duration and intensity of NF-kappa B activity determine the severity of endotoxin-induced acute lung injury. J Immunol. 2006; 176:4995-5005.

27. Jaiswal AK. Nrf2 signaling in coordinated activation of antioxidant gene expression. Free Radical Bio Med. 2004; 36:1199-1207.
28. Marzec JM, Christie JD, Reddy SP, Jedlicka AE, Vuong H, Lanken PN, Aplenc R, Yamamoto T, Yamamoto M, Cho HY, Kleeberger SR. Functional polymorphisms in the transcription factor NRF2 in humans increase the risk of acute lung injury. Faseb Journal. 2007; 21:2237-2246.

29. Reddy NM, Potteti HR, Mariani TJ, Biswal S, Reddy SP. Conditional Deletion of Nrf2 in Airway Epithelium Exacerbates Acute Lung Injury and Impairs the Resolution of Inflammation. Am J Resp Cell Mol. 2011; 45:1161-1168.

30. Choi JY, Kwun MJ, Kim KH, Lyu JH, Han CW, Jeong HS, Ha KT, Jung HJ, Lee BJ, Sadikot RT, Christman JW, Jung SK, Joo M. Protective Effect of the Fruit Hull of Gleditsia sinensis on LPS-Induced Acute Lung Injury Is Associated with Nrf2 Activation. Evid-Based Compl Alt. 2012.

31. Zhu GF, Guo HJ, Huang Y, Wu CT, Zhang XF. Eriodictyol, a plant flavonoid, attenuates LPS-induced acute lung injury through its antioxidative and anti-inflammatory activity. Experimental and therapeutic medicine. 2015; 10:2259-2266.

32. Jiang L, Liu Y, He P, Chen J, Liu S, Tan N. Geraniin ameliorates cisplatin-induced nephrotoxicity in mice. Free radical research. 2016; 50:813-819.

33. Lv H, Zhu C, Liao Y, Gao Y, Lu G, Zhong W, Zheng Y, Chen W, Ci X. Tenuigenin ameliorates acute lung injury by inhibiting NF-kappaB, MAPK signalling pathways. Respir Physiol Neurobiol. 2015; 216:43-51. 